\title{
African traditional abdominal massage in pregnancy resulting in antepartum uterine rupture, abruptio placenta and foetal demise - a case report
}

\author{
Simeon C. Amadi*, Peter A. Awoyesuku, Rose S. Iwo-Amah, Sandra U. Ibeabuchi
}

Department of Obstetrics and Gynaecology, Rivers State University Teaching Hospital, (RSUTH) Port Harcourt, Rivers State, Nigeria

Received: 17 November 2021

Accepted: 06 December 2021

\section{*Correspondence:}

Dr. Simeon C. Amadi,

E-mail: amachijio@yahoo.com

Copyright: () the author(s), publisher and licensee Medip Academy. This is an open-access article distributed under the terms of the Creative Commons Attribution Non-Commercial License, which permits unrestricted non-commercial use, distribution, and reproduction in any medium, provided the original work is properly cited.

\begin{abstract}
The practice of abdominal massage dates to years ago and associated with foetal and maternal morbidity and mortality when undertaken by untrained traditional birth attendants in our setting. We present a 30 -year old $\mathrm{G}_{3} \mathrm{P}^{+0}$ with uterine rupture and intra-uterine foetal death following abdominal massage. She was resuscitated and had emergency exploratory laparotomy and repair of uterine rupture.
\end{abstract}

Keywords: African traditional massage, Pregnancy, Uterine rupture, Abruptio placenta, Foetal demise

\section{INTRODUCTION}

The practice of abdominal massage in general and in pregnancy dates back to thousands of years ago and it has been practiced in many cultures and regions of the world including Asia, Central America, Sweden, and China, and in some countries in Africa like Egypt and Nigeria. ${ }^{1-4}$ Abdominal massage is a prevalent practice among untrained traditional birth attendants in the Niger delta region of Nigeria especially in the rural areas. ${ }^{5}$ Although abdominal massage during pregnancy has been reported to be helpful, especially when performed by trained personnel, there is no scientifically proven benefit of this tradition in pregnancy and it is even detrimental to the gravidae and/or their foetuses in certain clinical conditions e.g. placenta praevia, previous uterine scar, ectopic pregnancy, and threatened miscarriage. ${ }^{3,6}$ Abdominal massage is a risk factor for uterine rupture, abruptio placenta and the attendant maternal and foetal morbidity and mortality. ${ }^{7,8}$ Uterine rupture and/or abruption placenta are catastrophic obstetric events associated with foetal and maternal morbidity and mortality, especially when they are not recognised early and/or intervention is not prompt. ${ }^{9}$
The uterine rupture may occur spontaneously, or due to trauma or as a result of the dehiscence of existing uterine scar. ${ }^{10,11}$ It can either occur in women with an unscarred uterus or a uterus with a previous surgical scar. ${ }^{12}$ It can occur during pregnancy, early in labour or following a prolonged labour, most frequently near or at term. ${ }^{11}$

Uterine rupture due to deliberate trauma to the uterus by untrained traditional birth attendants with permission of the pregnant woman during abdominal massage in this $21^{\text {st }}$ century is rare in developed societies but still occurs in developing societies like ours. ${ }^{5}$ The clinical scenario of this patient is a very rare presentation of uterine rupture in our hospital. This case report will add to the existing body of knowledge and bring attention to the menace of abdominal massage by untrained personnel in our society and its attendant dangers.

\section{CASE REPORT}

We present a 30-year-old woman, booked defaulter, $\mathrm{G}_{3} \mathrm{P}^{+0}$ (with one living child) who was rushed into the labour ward at 37 weeks of gestation with abdominal pain 
and vaginal bleeding both of 2 hours duration. The abdominal pain was severe, generalised, and persistent. The vaginal bleeding was initially mild but later became profuse with associated passage of blood clots with dizziness. These symptoms were preceded by abdominal massage in the home of a traditional birth attendant (TBA) few hours prior to presentation. The aim of the massage was to aid vaginal delivery when labour ensues. There was no drainage of liquor and no labour pain before the massage.

The index pregnancy was essentially uneventful prior to the onset of the symptoms. Her antenatal care was in our centre, and she was being planned for trial of labour after a previous caesarean section. She had a fresh stillborn male baby in her first pregnancy in 2016 at the home of a traditional birth attendant. The puerperium was normal. In 2017, she had antenatal care and an uneventful pregnancy at a Health centre but during labour, she went to the home of a TBA where the labour was complicated by cephalopelvic disproportion. She was taken to a private Hospital where she had an emergency caesarean section with the delivery of a live $3.5 \mathrm{~kg}$ female baby. The baby was breastfed. The puerperium was normal. The baby was alive and well.

She had normal regular menstrual periods. There was no significant past medical and surgical history. She had no drug allergy. She was the only wife of a businessman. There was no family history of systemic illnesses.

On examination at presentation, she was in shock with marked pallor. Her abdomen was distended There was marked generalised abdominal tenderness. The fundal height and fetal presentation could not be determined due to uterine board-like rigidity and tenderness. The foetal heart sound was not heard, even with the Sonicaid. There was active vaginal bleeding with passage of blood clots. The cervix was posterior, soft, and uneffaced. The cervical os admitted the tip of a finger. The gloved examining fingers were stained with frank blood.

Diagnosis of abroptio placenta with intrauterine fetal demise (IUFD) and hypovolemic shock and suspected uterine rupture was made. She was resuscitated with intravenous fluid, $100 \%$ oxygen through nasal prongs and analgesics. Her packed cell volume was $23 \%$. Bed side clotting time was normal. Four units of blood were grouped and cross matched for her. She and her relatives were counselled on her condition, and she had emergency exploratory laparotomy after informed consent was obtained for the procedure. Findings at surgery were haemo-peritoneum of about 300 millilitres, a dense adhesion band that attached the anterior fundal wall of the uterus to the anterior abdominal wall, avulsion of complete uterine wall with the adhesion band, intact previous scar, fresh still born $2.8 \mathrm{~kg}$ male baby and retro-placental blood clots (Figure 1). The postero-fundal placenta weighed 0.6 $\mathrm{kg}$. The baby was delivered through low transverse uterine incision because the rupture was not big enough and extension of the injury at that fundal region needed to be avoided. Both the incision and the rupture site were repaired, and haemostasis was secured. She received two units of blood intra-operatively and two units of blood post-operatively.

Her post-operative period was uneventful. She received antibiotics and analgesics. Her post-transfusion packed cell volume was $28 \%$. She was counselled on the outcome of the surgery. She was discharged on the $5^{\text {th }}$ postoperative day on double dose haematinics and oral antibiotics. She was seen two weeks later in the postnatal clinic and had no complain. Clinical examination revealed no abnormality. She was counselled and given appointment for her $6^{\text {th }}$ week visit. Clinical evaluation at the $6^{\text {th }}$ week visit, revealed no abnormality. She was further counselled and referred to the family planning clinic for contraception.

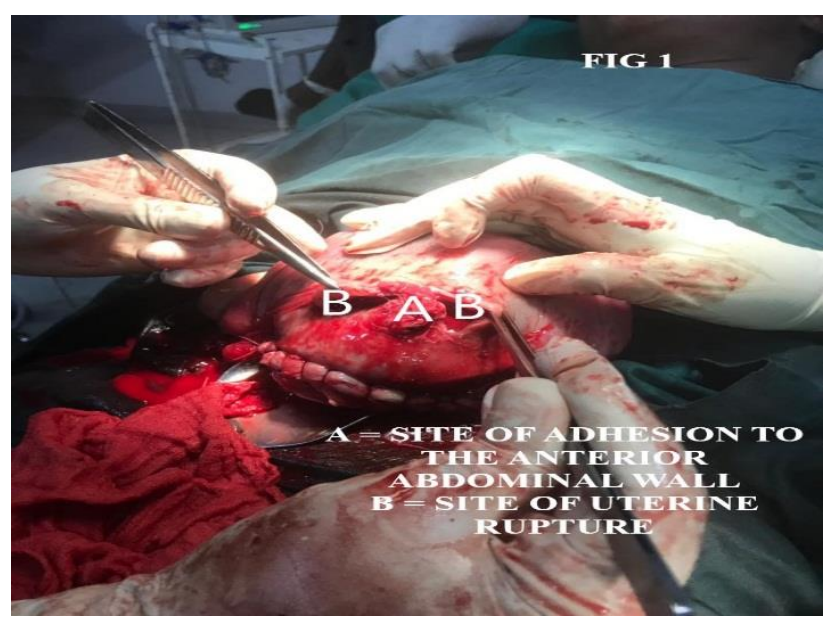

Figure 1: A) Site of adhesion; and (B) site of uterine rupture.

\section{DISCUSSION}

Abdominal massage during pregnancy has been said to be useful based on individual perception or judgment but studies have shown a correlation between severe adverse pregnancy outcomes (such as abruption placenta, uterine rupture, foetal morbidity, foetal mortality, maternal morbidity, and maternal mortality) and abdominal massage. $7,8,13,14$ The index patient had a traumatic complete rupture of the uterus, abruptio placenta and intra-uterine foetal death with maternal morbidity.

Development of severe adhesions after a caesarean section is a possibility, but the scenario of severe (dense) adhesions which fixed the fundus of the uterus to the anterior abdominal wall and causing the avulsion (rupture) of the uterine muscle during abdominal massage is uncommon. The major factors responsible for the uterine rupture in this patient was the trauma occasioned by the abdominal massage, the dense adhesions from the previous caesarean section and the aversion to caesarean section resulting in default from antenatal care. The risks are made 
worse by ignorance, poverty, non-utilization of available services, cultural beliefs. ${ }^{13,15}$

Our patient presented with dizziness, generalized abdominal pain, absent foetal movements, signs of hypovolaemic shock, abdominal tenderness, absent foetal heart tone and active vaginal bleeding with passage of blood clots. Although our patient came in with a dead foetus, foetal bradycardia is the most common abnormality associated with uterine rupture in those with live baby. ${ }^{16}$ Absent foetal heart rate tracing on a cardiotocogram (CTG) is pathognomonic of uterine rupture. ${ }^{17}$ The absence of foetal heart sounds is obviously an ominous sign and requires an ultrasound confirmation of absent foetal cardiac activity. ${ }^{17}$ This was not done for this patient because of her clinical state which warranted immediate surgical intervention without delays.

Active resuscitation and early surgical intervention, as was done in this patient, are key to successful management of uterine rupture. ${ }^{12}$ The surgical options for uterine rupture at laparotomy include repair of the rupture alone, repair with bilateral tubal ligation, sub-total abdominal hysterectomy, and total abdominal hysterectomy. ${ }^{12,17}$ This patient had repair of the ruptured uterus alone. The tear on the fundal aspect of the uterus was not extensive and followed the transverse plane in much of its course (Figure 1). The repair alone was a shorter and safer surgery for this woman with haemodynamic instability. She had one living child and desired future fertility. The conservation of her childbearing ability in our society where there is high premium on childbearing would aid her psycho-social well-being and survival of her marriage after these catastrophic and unexpected obstetric events. Given the site of the rupture, there is risk of repeat rupture in her next pregnancy hence early antenatal booking with close monitoring and proper supervision in subsequent pregnancy are key to favourable outcome. She was appropriately counselled on these issues before discharge from the hospital. The counselling was also re-enforced, and the issues re-emphasized during her follow-up visits. In view of the detailed counselling, it is expected that future catastrophic events will be averted in this woman with a previous history of default from antenatal care.

\section{CONCLUSION}

Uterine rupture and abruption placenta remain a cause of maternal and foetal morbidity and mortality in our environment. Abdominal massage (a risk factor for these conditions) is also prevalent in this part of Nigeria with its attendant complications as seen in this patient. Public awareness, enlightenment campaigns and education of the women and their families on the dangers of abdominal massage will help to prevent the obstetric problems associated with this societal menace.

Funding: No funding sources Conflict of interest: None declared

Ethical approval: Not required

\section{REFERENCES}

1. The Arvigo Techniques of Maya Abdominal Therapy. Available at: https://arvigotherapy.com/. Accessed on 20 October 2021.

2. Malcolm P, Maura G, Juddy T. Thousand-year-old depictions of massage abortion; FFPRHC J Fam Plann Reprod Health Care. 2007;33:4-8.

3. Calvert RN. "Swedish Massage" Massage magazine. Available

at: https://www.massagemag.com/archives/Magazine/20 02/issue100/history 100.php. Accessed on 20 October 2021.

4. What is Traditional Chinese Massage? Available at: 365tcm.com.2008-10-17. Accessed on 20 October 2021.

5. Addah AO, Ibrahim IA, Ikeanyi EM. The Prevalence and Predictors of Abdominal Massage Among Pregnant Women Attending Antenatal Care at The Niger Delta University Teaching Hospital, Okolobiri Nigeria. Nigerian Health J. 2021;21(1):10-9.

6. Ugboma HA, Akani CI. Abdominal massage: Another cause of maternal mortality. Niger $\mathrm{J}$ Med. 2004;13:259-62.

7. Abasi JI, Jeremiah I, Ekine AA. Risk factors and pregnancy outcome of placental abruption at the Niger Delta University Teaching Hospital, Okolobiri, South-south Nigeria. $\mathrm{Br} \mathrm{J}$ Med Med Res. 2015;5(8):1000-6.

8. Wagle RR, Sabroe S, Nielsen BB. Socioeconomic and physical distance to the maternity hospital as predictors for place of delivery: An observation study from Nepal. BMC Pregnancy and Childbirth. 2004;4:8.

9. Gibbins KJ, Weber T, Holmgren CM, Porter TF, Varner MW, Manuck TA. Maternal and fetal morbidity associated with uterine rupture of the unscarred uterus. Am J Obstet Gynecol. 2015;213(3):382.

10. Herrera FA, Hassanein AH, Bansal V. Atraumatic spontaneous rupture of the non-gravid uterus. J Emerg Trauma Shock. 2011;4(3):439.

11. Guseh SH, Carusi DA, Tinelli A, Gargiulo AR. Spontaneous Uterine Rupture Prior to Twenty Weeks of Gestation. Dans Management and Therapy of Early Pregnancy Complications. Cham: Springer International Publishing. 2016;255-67.

12. Gardeil F, Sean D, Turner MJ. Uterine rupture in pregnancy reviewed. Euro J Obstet Gynecol Reprod Biol. 1994;56(2):107-10.

13. Eze JN, Ibekwe PC. "Uterine rupture at a secondary hospital in Afikpo, Southeast Nigeria". Singapore Med J. 2010;51:506-11.

14. Ekine AA, Harry CT, Ibrahim IA, Abasi I. Ectopic pregnancy in NDUTH, Okolobiri- 5 year case retrospective review. Indian J Med Res Phar Sci. 2014;1:7-10.

15. Eguzo KN, Umezurike CC. "Rupture of unscarred uterus: a multi-year cross-sectional study from 
Nigerian Christian Hospital, Nigeria”. Int J Reprod Contracept Obstet Gynecol. 2013;2:657-70.

16. Guiliano M, Closset E, Therby D, LeGoueff F, Deruelle P, Subtil D. Signs, symptoms, and complications of complete and partial uterine ruptures during pregnancy and delivery. Eur J Obstet Gynecol Reprod Biol. 2014;179:130-4.

17. Ozdemir I, Yucel N, Yucel O. Rupture of the pregnant uterus: a 9-year review. Arch Gynecol Obstet. 2005;272(3):229-31.
Cite this article as: Amadi SC, Awoyesuku PA, Iwo-Amah RS, Ibeabuchi SU. African traditional abdominal massage in pregnancy resulting in antepartum uterine rupture, abruptio placenta and foetal demise - a case report. Int J Reprod Contracept Obstet Gynecol 2022;11:265-8. 